\title{
Low-threshold laser in a high-index-contrast double tungstate waveguide
}

\author{
D.Geskus, S.Aravazhi, K. Wörhoff, and M. Pollnau \\ Integrated Optical MicroSystems (IOMS) Group, MESA+ Institute for Nanotechnology, \\ University of Twente, P.O. Box 217, 7500 AE Enschede, The Netherlands
}

The potassium double tungstates $\mathrm{KY}\left(\mathrm{WO}_{4}\right)_{2}, \mathrm{KGd}\left(\mathrm{WO}_{4}\right)_{2}$, and $\mathrm{KLu}\left(\mathrm{WO}_{4}\right)_{2}$ are recognized as excellent host materials for rare-earth-ion-doped lasers, see Ref. [1] and Refs. therein. Especially $\mathrm{KY}\left(\mathrm{WO}_{4}\right)_{2}: \mathrm{Yb}^{3+}$, hereafter abbreviated as KYW: $\mathrm{Yb}^{3+}$, exhibits large absorption and emission cross-sections, a small quantum defect [2], and laser emission with high slope efficiencies. Liquid phase epitaxy (LPE) has been used to grow thin layers of $\mathrm{KYW}: \mathrm{Yb}^{3+}$ onto pure KYW substrates and planar waveguide lasing with slope efficiencies up to $80 \%$ has been demonstrated in samples doped with 1.2-2.4\% $\mathrm{Yb}^{3+}$ [3]. Recently, similar results have been obtained under diode pumping with a monolithic cavity [4]. The main disadvantage of this approach for fabricating integrated devices is the fact that the choice of rather low $\mathrm{Yb}^{3+}$ concentration is governed by the need to optimize the laser properties, resulting in a low refractive-index contrast between layer and substrate of only a few $\times 10^{-4}$. This inhibits downscaling the waveguide thickness to 1-2 $\mu \mathrm{m}$.

Here we report on laser emission from an enhanced-index-contrast waveguide fabricated by co-doping the active layer with $\mathrm{Lu}$ and $\mathrm{Gd}$ ions. Both, $\mathrm{Lu}^{3+}$ and $\mathrm{Gd}^{3+}$ possess higher electron densities than $\mathrm{Y}^{3+}$, thus increasing the refractive index. Simultaneously, this approach provides the possibility for growing lattice-matched layers, as these two ions change the lattice constants of KYW in opposite directions. The active layer was overgrown by an undoped KYW layer (Fig. 1). The buried $\mathrm{KYW}: \mathrm{Lu}^{3+}, \mathrm{Gd}^{3+}, \mathrm{Yb}^{3+}$ layer exhibits a refractive-index contrast of $7.5 \times 10^{-3}$ [5], thus allowing for a 1.2- $\mu \mathrm{m}$-thin layer and resulting in a high confinement of pump and laser modes.

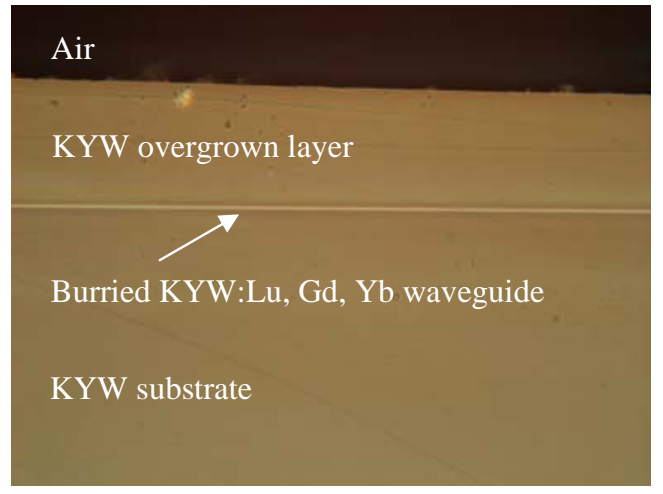

Fig. 1 Microscope image (50X) shows endface of buried waveguide

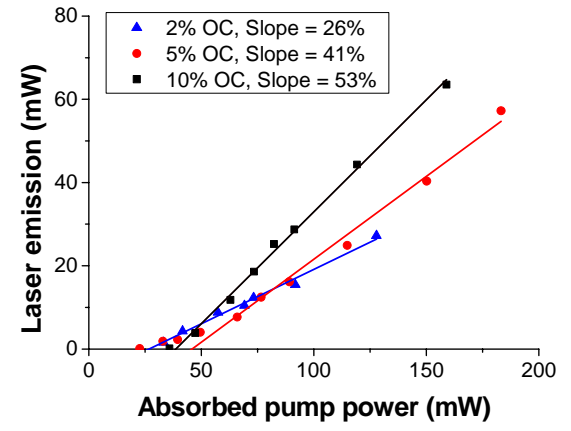

Fig. 2 Laser performance of device

The experimental results were obtained with a 5-mm-long planar waveguide with nominal concentrations of $25.3 \% \mathrm{Lu}^{3+}, 13 \% \mathrm{Gd}^{3+}$, and $1.7 \% \mathrm{Yb}^{3+}$. The laser cavity was formed by butt-coupling dielectric mirrors to the waveguide endfaces. The incoupling mirror had a reflectance of $99.8 \%$ at the laser wavelength, while for the outcoupling mirror reflectances of $98 \%, 95 \%$ and $90 \%$ were tested. Two cylindrical lenses were used to adapt the Ti:Sapphire pump mode to the laser mode, resulting in a pump waist of $\sim 30 \mu \mathrm{m}$ in horizontal direction. The highest slope efficiency of 53\% was achieved with $10 \%$ outcoupling (Fig. 2). The maximum extracted laser power was $60 \mathrm{~mW}$, limited by our attempt to avoid potential damage of the incoupling end-facet by high pump intensity. The laser threshold of $25 \mathrm{~mW}$ versus absorbed pump power for $2 \%$ outcoupling is low compared to previous experiments $[3,4]$ and reveals one of the advantages of the high optical confinement obtained by the enhanced index contrast. The emission wavelength varied from $1010 \mathrm{~nm}$ to $1040 \mathrm{~nm}$, strongly depending on the alignment, which was probably caused by the etalon effects of the gaps between the mirrors and the endfaces.

These results on lasing of enhanced-index-contrast KYW planar waveguides form the basis for further onchip integration by implementation of channel waveguides and on-chip resonators.

\section{References}

[1] M. Pollnau, Y.E. Romanyuk, F. Gardillou, C.N. Borca, U. Griebner, S. Rivier, and V. Petrov, "Double tungstate lasers: From bulk toward on-chip integrated waveguide devices”, IEEE J. Select. Topics Quantum Electron. 13, 661 (2007).

[2] P. Klopp, V. Petrov, and U. Griebner, "Potassium ytterbium tungstate provide the smallest laser quantum defect”, Jpn. J. Appl. Phys. 42, L246 (2003).

[3] Y.E. Romanyuk, C.N. Borca, M. Pollnau, S. Rivier, V. Petrov, and U. Griebner, "Yb-doped $\mathrm{KY}\left(\mathrm{WO}_{4}\right)_{2}$ planar waveguide laser”, Opt. Lett. 31, 53 (2006).

[4] F. Bain, A.A. Lagatsky, S.V. Kurilchik, V.E. Kisel, S.A. Guretsky, A.M. Luginets, I.M. Kolesova, C.T.A. Brown, W. Sibbett, N.V. Kuleshov, “Diode-pumped Yb:KYW planar-waveguide lasers”, EPS-QEOD Europhoton Conference on Solid-State and Fiber Coherent Light Sources, Paris, France, 2008, Conference Digest, paper ThD1.

[5] F. Gardillou, Y.E. Romanyuk, C.N. Borca, R.P. Salathé, and M. Pollnau, "Lu, Gd co-doped KY(WO$\left.{ }_{4}\right)_{2}$ :Yb epitaxial layers: Towards integrated optics based on $\mathrm{KY}\left(\mathrm{WO}_{4}\right)_{2}$ ”, Opt. Lett. 32, 488 (2007). 